\title{
The effect of atmospheric nudging on the stratospheric residual circulation in chemistry-climate models
}

\section{Chrysanthou et al.}

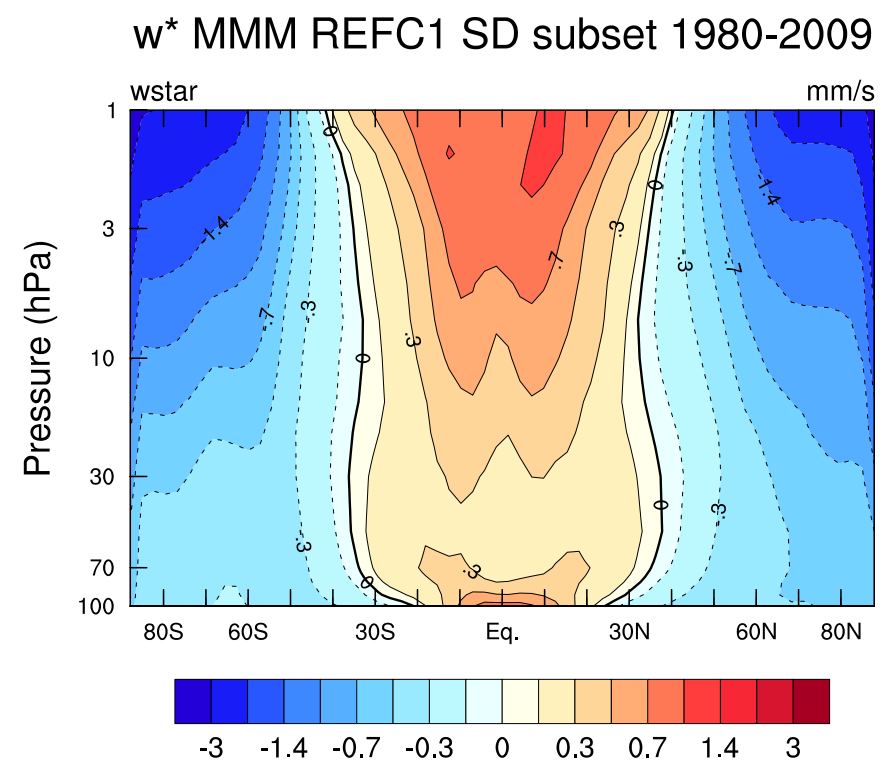

Figure S1: MMM $\bar{w}^{*}$ from annual means latitude/height cross section of the stratosphere for the REF-C1 runs that have also run the REF-C1SD experiment. Apart from the upper stratosphere no real differences can be found between this MMM and the MMM from all the REF-C1 simulations (10).
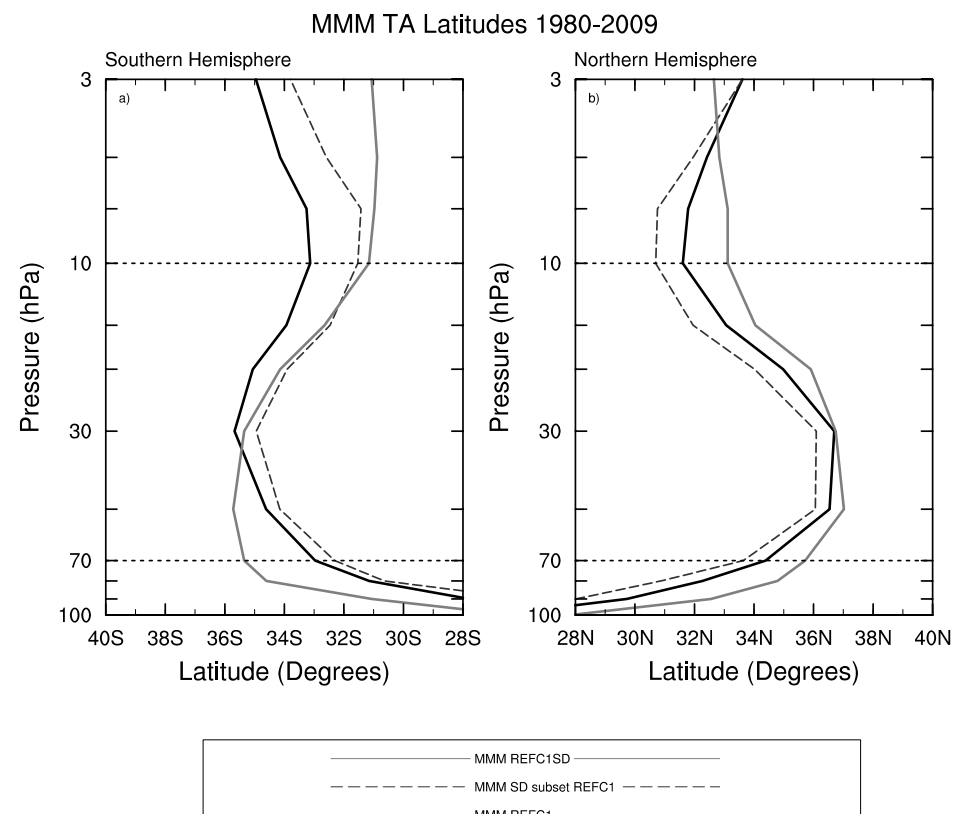

(1)

Figure S2: Vertical profiles of climatological turnaround latitudes in the stratosphere for the MMM of the REFC1 runs (MMM REFC1), of the REF-C1 runs that have also run the REF-C1SD experiment (MMM SD subset REFC1) and of the REFC1SD runs for Southern Hemisphere (a) and Northern Hemisphere (b). 


\section{Annual mean upward mass flux at $10 \mathrm{hPa}$}

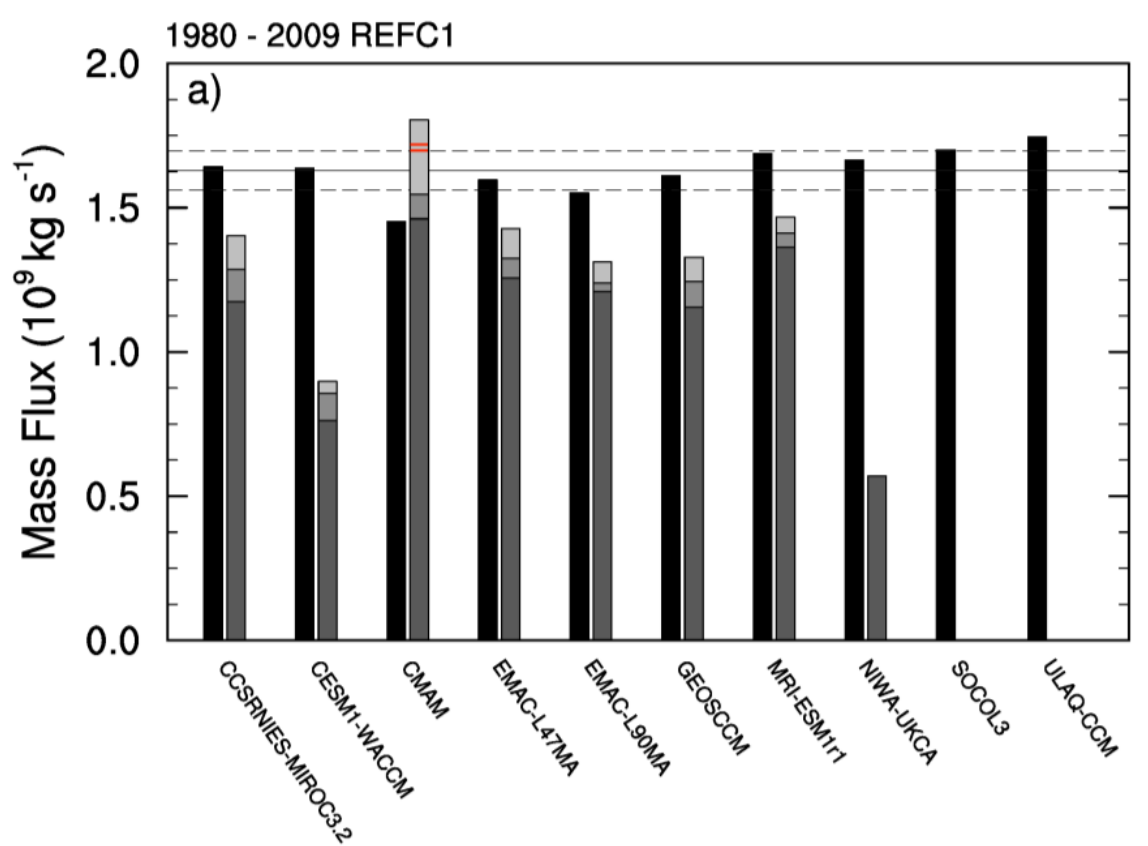

Annual mean upward mass flux at $10 \mathrm{hPa}$

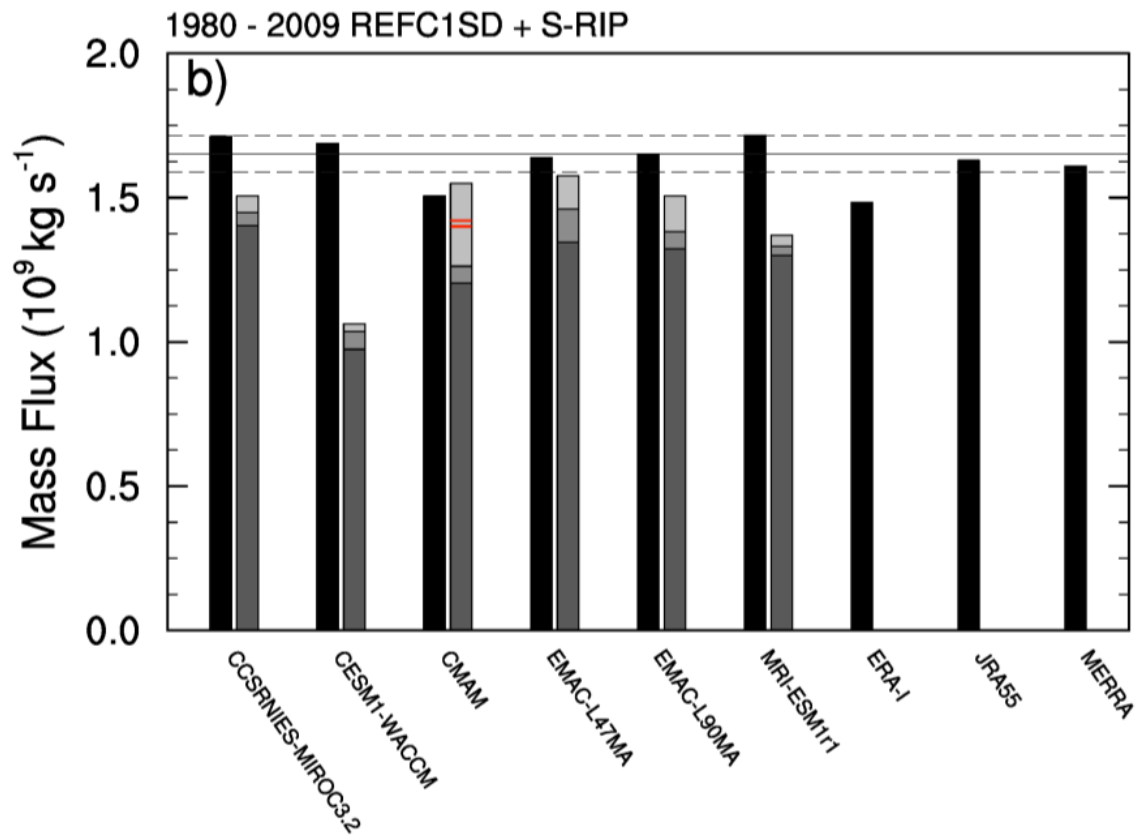

Figure S3. Tropical upward mass flux at $10 \mathrm{hPa}$ (left bars) along with downward control calculations (right bars) showing contributions from EPFD (dark grey), OGW (mid-grey), and NOGW (light grey) for (a) REF-C1 and (b) REF-C1SD. For CMAM the NOGWD contributes negatively to TUMF and is indicated with two red horizontal lines inside the lighter grey bar. 


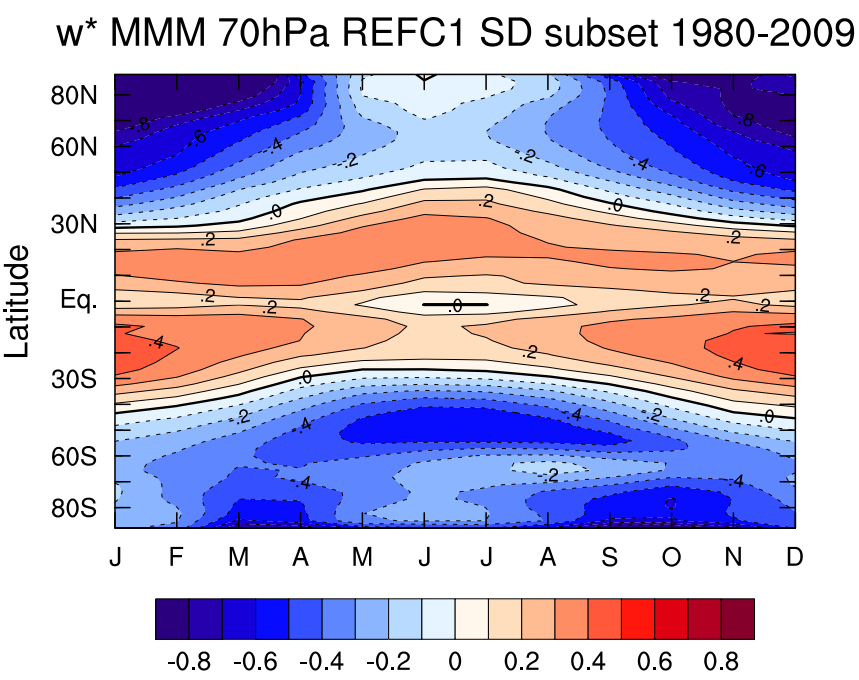

Figure S4: MMM $\bar{w}^{*}$ from annual means annual cycle of the stratosphere for the REF-C1 runs that have also run the REF-C1SD experiment.

\section{REFC1 MLR Regression Coefficients}

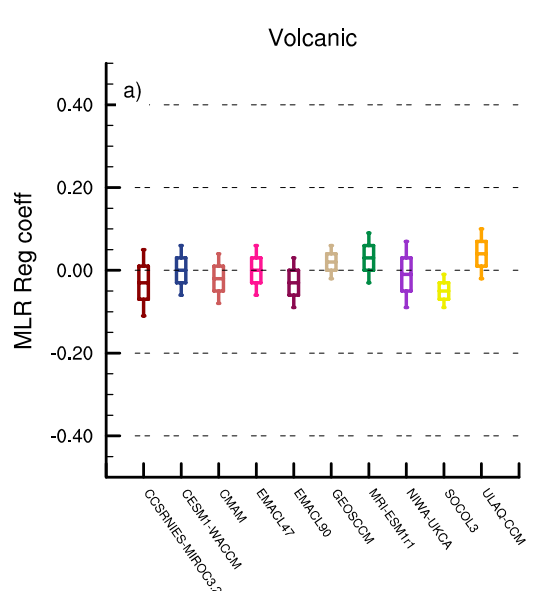

QBO1

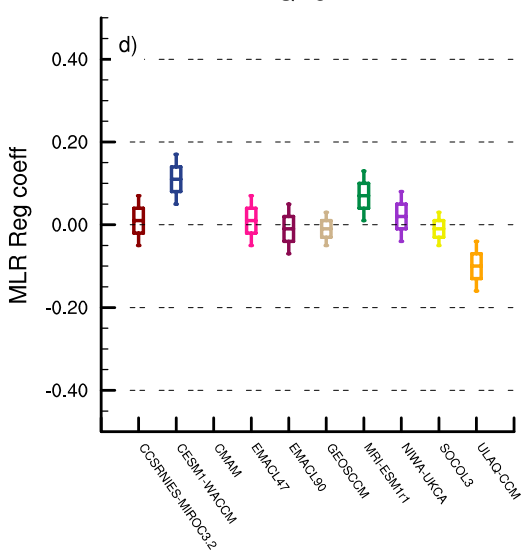

ENSO

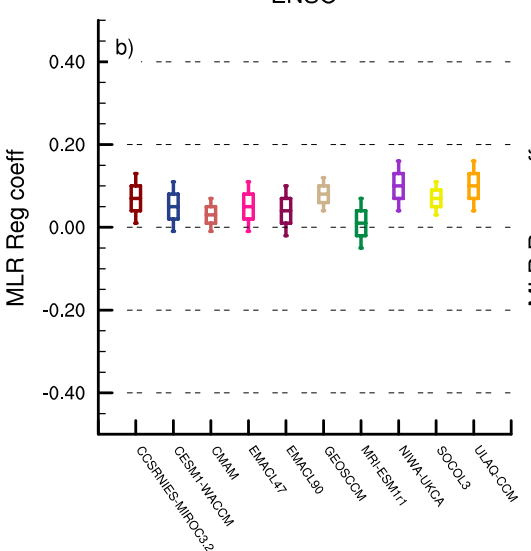

QBO2

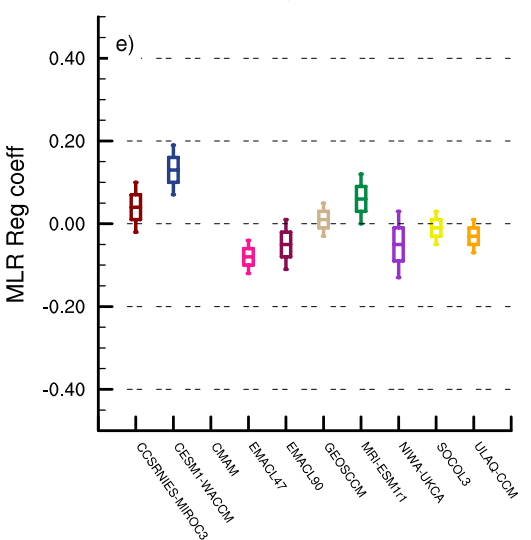

Linear Trend
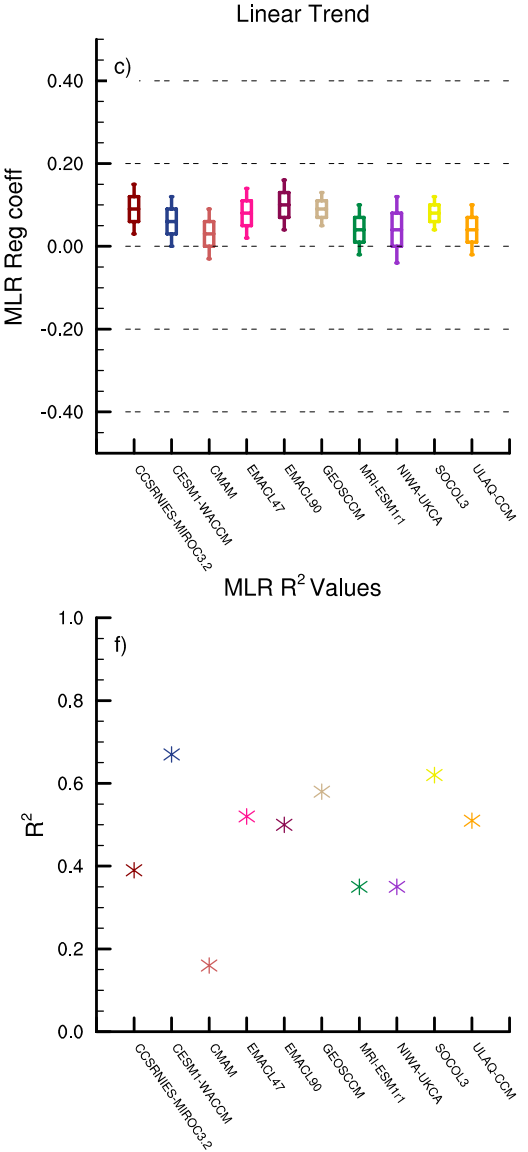

Figure S5. Partial regression coefficients of each regressor \pm 2 standard errors and $\mathrm{R}^{2}$ values output from the MLR on the TUMF at $70 \mathrm{hPa}$ for REF-C1 simulations. 


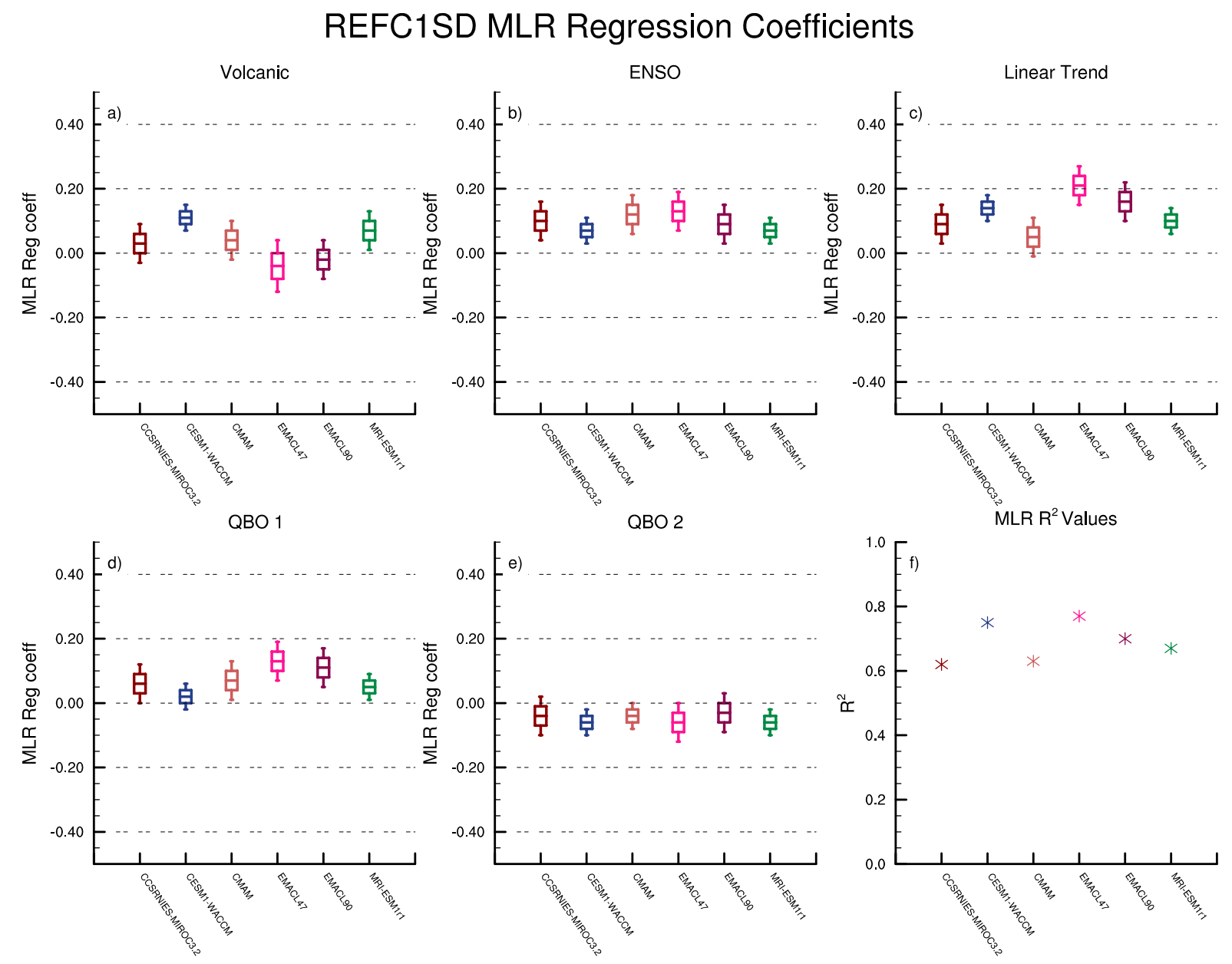

Figure S6. Partial regression coefficients of each regressor \pm 2 standard errors and $\mathrm{R}^{2}$ values output from the MLR on the TUMF at $70 \mathrm{hPa}$ for REF-C1SD simulations. 


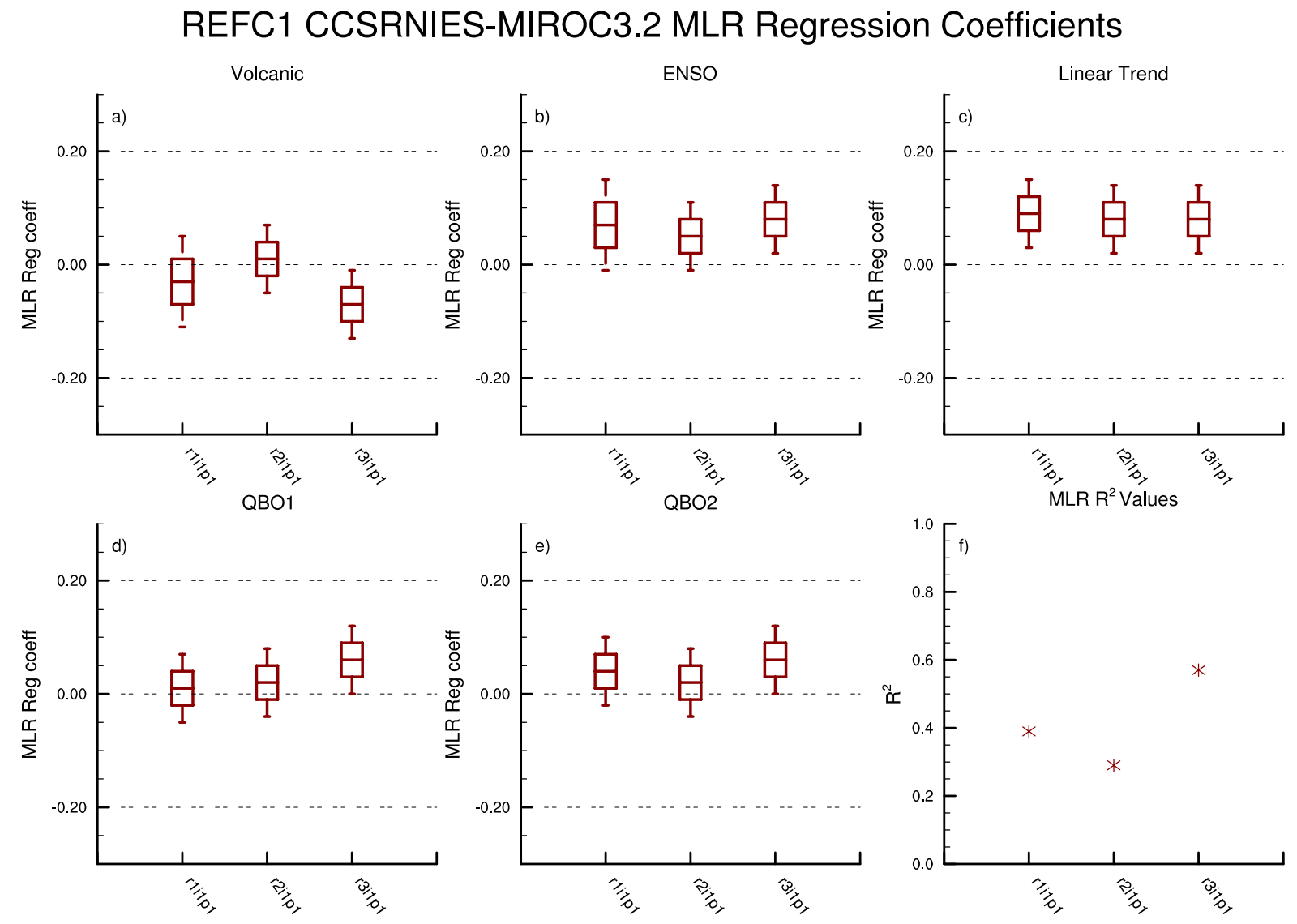

Figure S7. Regression coefficients of each regressor \pm 2 standard errors and $\mathrm{R}^{2}$ values output from the MLR on the TUMF at $70 \mathrm{hPa}$ for all available REF-C1 CCSRNIES-MIROC3.2 ensemble members. 


\section{REFC1 CESM1-WACCM MLR Regression Coefficients}
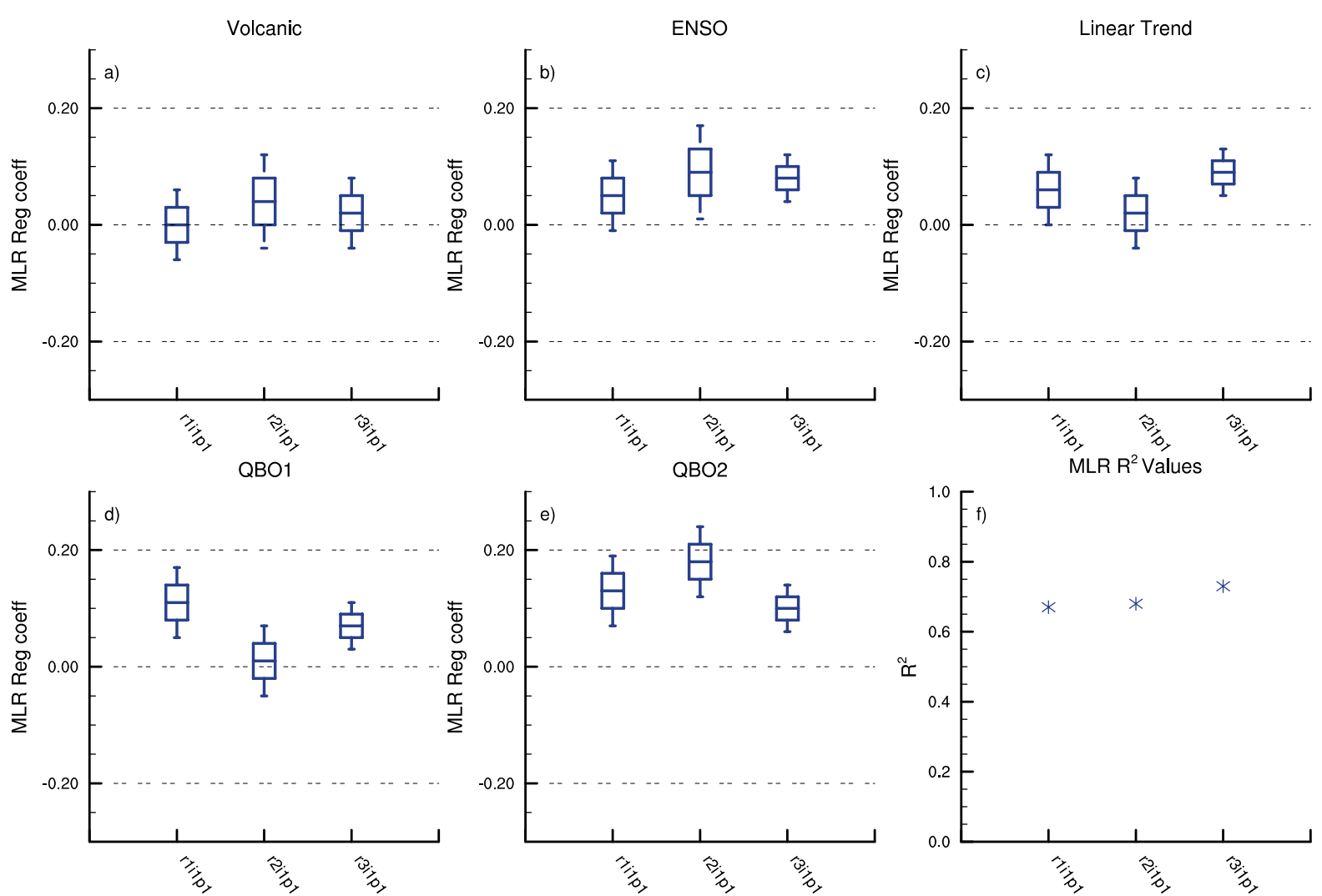

Figure S8. Regression coefficients of each regressor \pm 2 standard errors and $\mathrm{R}^{2}$ values output from the MLR on the TUMF at $70 \mathrm{hPa}$ for all available REF-C1 CESM1-WACCM ensemble members. 

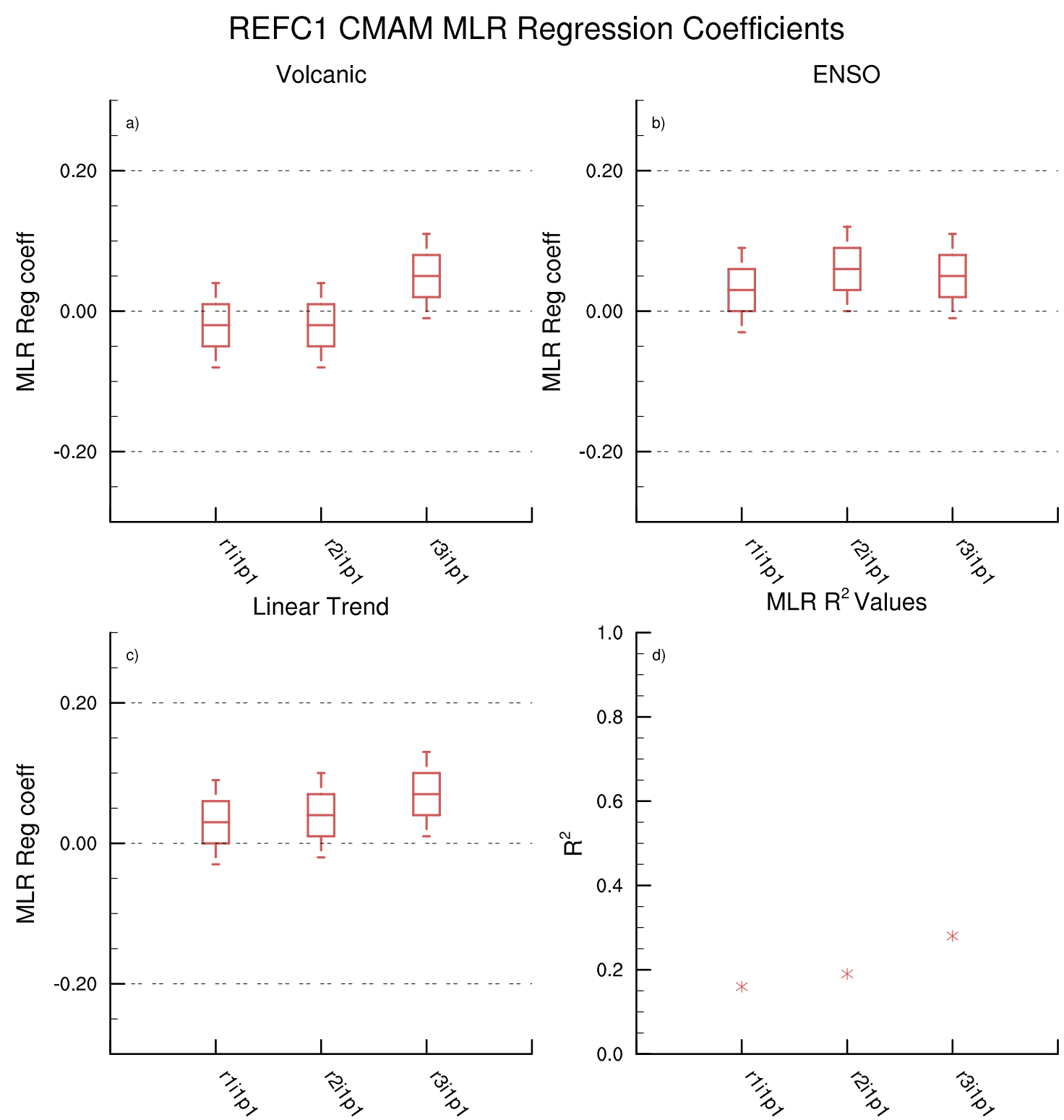

Figure S9. Regression coefficients of each regressor \pm 2 standard errors and $\mathrm{R}^{2}$ values output from the MLR on the TUMF at $70 \mathrm{hPa}$ for all available REF-C1 CMAM ensemble members. Note that CMAM does not simulate a QBO hence the QBO terms were omitted. 


\section{REFC1 NIWA-UKCA MLR Regression Coefficients}
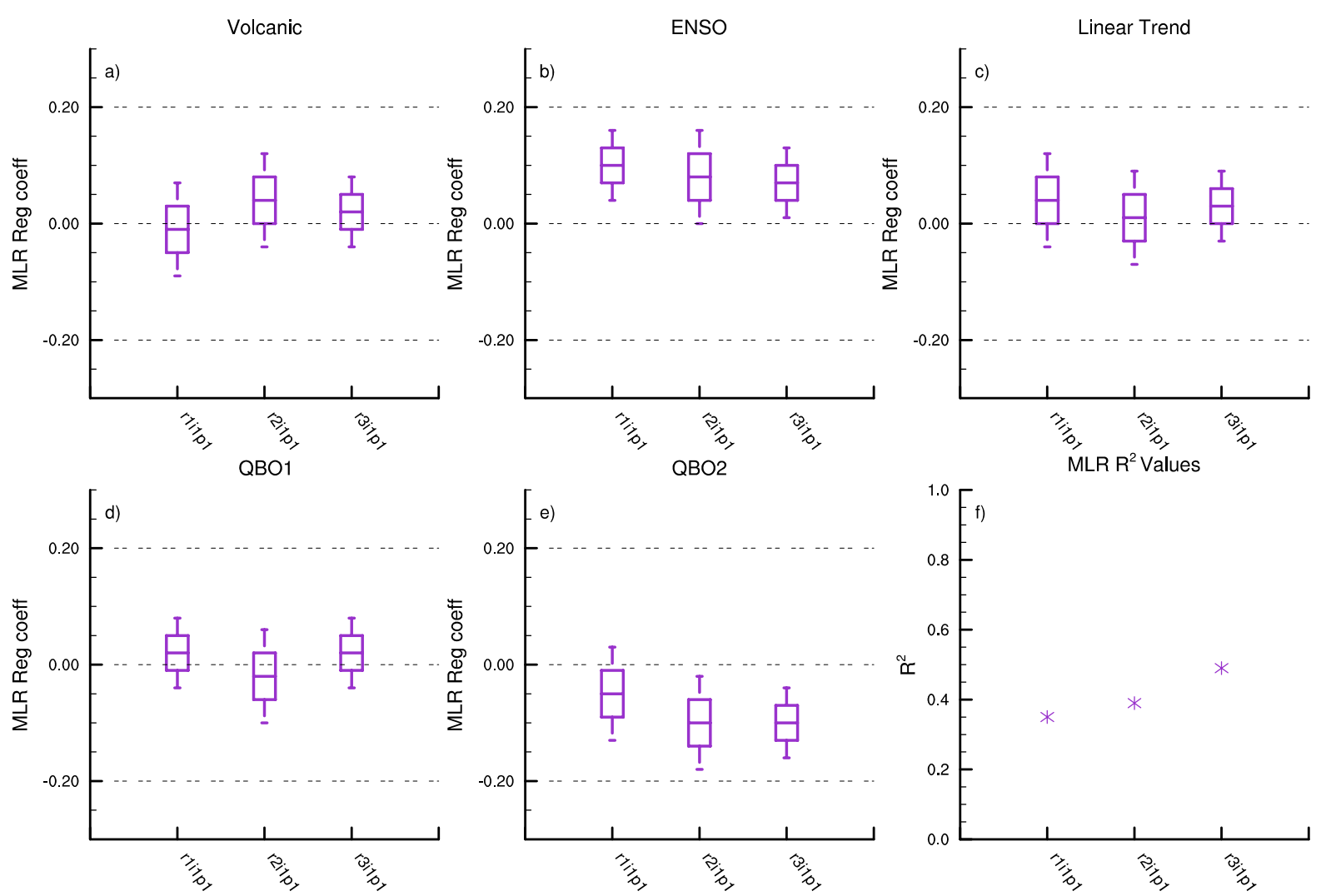

Figure S10. Regression coefficients of each regressor \pm 2 standard errors and $\mathrm{R}^{2}$ values output from the MLR on the TUMF at $70 \mathrm{hPa}$ for all available REF-C1 NIWA-UKCA ensemble members. 


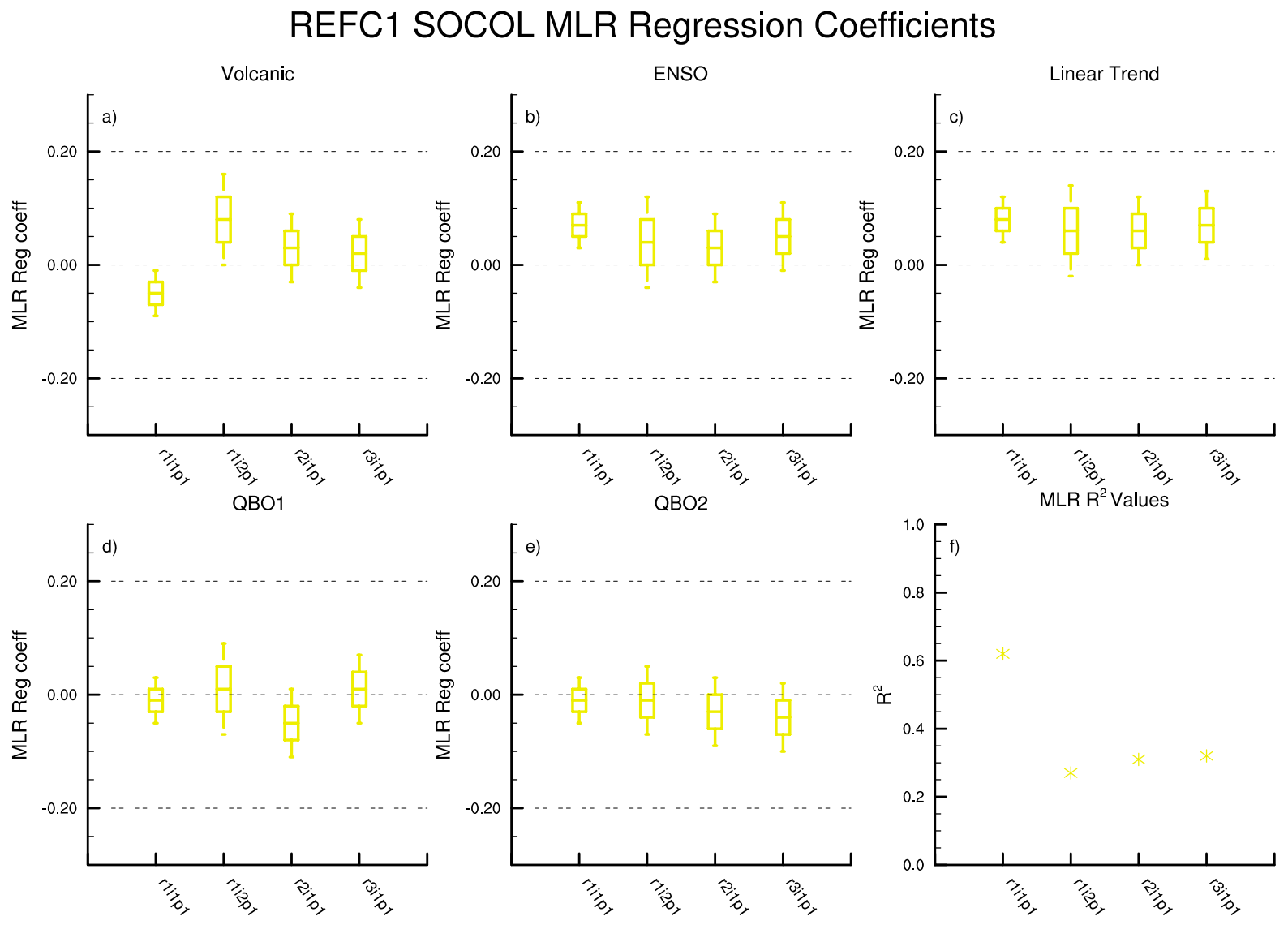

Figure S11. Regression coefficients of each regressor \pm 2 standard errors and $R^{2}$ values output from the MLR on the TUMF at $70 \mathrm{hPa}$ for all available REF-C1 SOCOL ensemble members. 


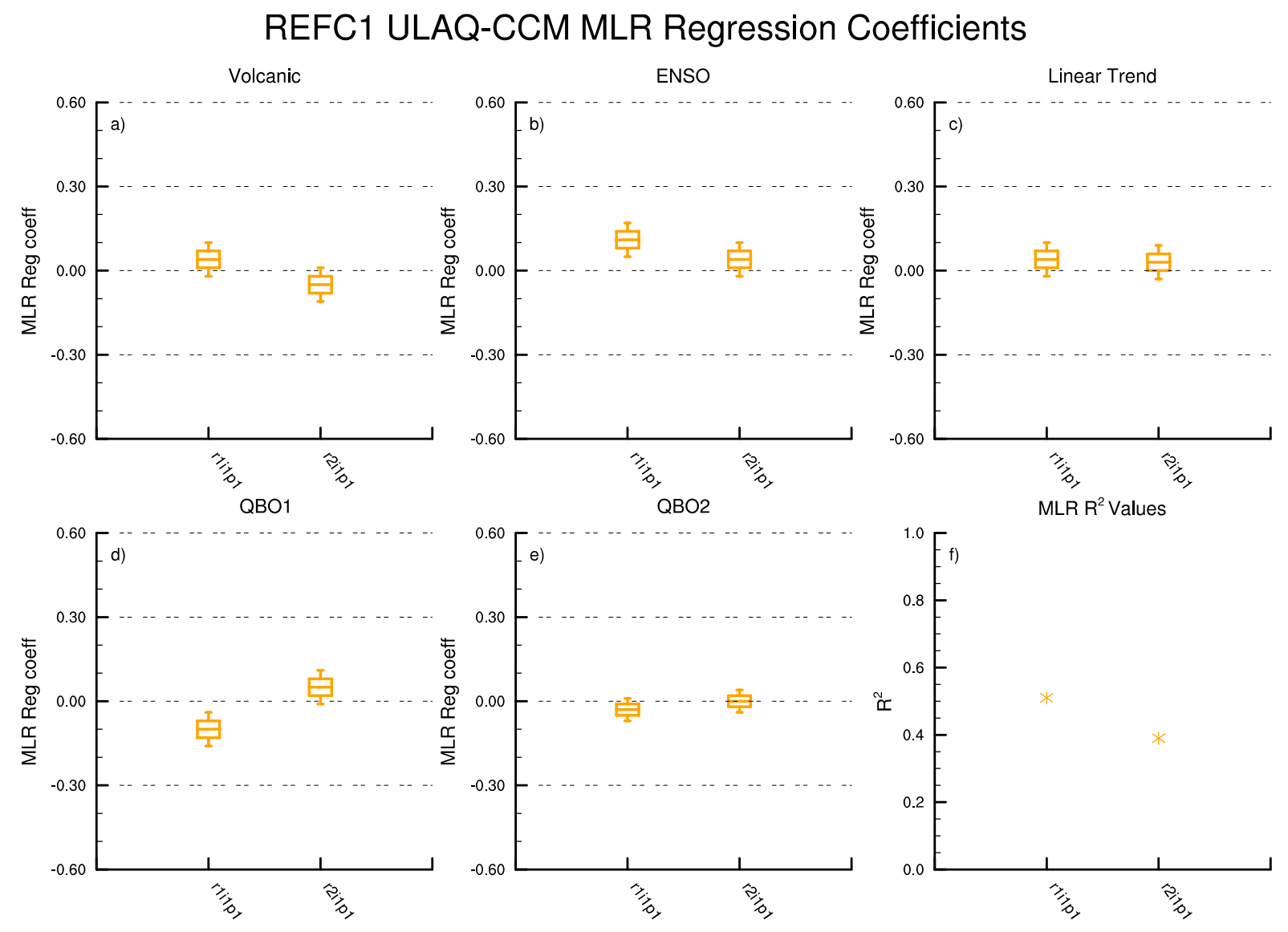

Figure S12. Regression coefficients of each regressor \pm 2 standard errors and $\mathrm{R}^{2}$ values output from the MLR on the tropical upward mass flux at $70 \mathrm{hPa}$ for all available REFC1 ULAQ-CCM ensemble members. 